\title{
Child-Pugh Class C15
}

National Cancer Institute

\section{Source}

National Cancer Institute. Child-Pugh Class C15. NCI Thesaurus. Code C146801.

A total score of 15 for hepatic function, corresponding to class $C$ in the Child-Pugh classification.. 